\title{
General anesthesia or conscious sedation in paroxysmal atrial fibrillation catheter ablation
}

\author{
Ondrej Moravec ${ }^{\mathrm{a}}$, Tomas Skala ${ }^{\mathrm{a}}$, Olga Klementova ${ }^{\mathrm{b}}$, Jitka Skalova ${ }^{\mathrm{b}}$, Martin Hutyra ${ }^{\mathrm{a}}$, Jan Precek ${ }^{\mathrm{a}}$, Marian Fedorco ${ }^{\mathrm{a}}$, \\ Vlastimil Cernicekc, Zbynek Tudos ${ }^{\mathrm{d}}$, Jana Zapletalovae ${ }^{\mathrm{e}}$, Milos Taborsky ${ }^{\mathrm{a}}$
}

Background. Catheter ablation of paroxysmal atrial fibrillation (AF) can be performed under general anesthesia or conscious sedation. The influence of type of anesthesiology care on procedural characteristics and ablation outcome in patients in whom intracardiac echocardiography (ICE) and elimination of adenosine-mediated dormant conduction (DC) is used is not entirely known.

Methods. 150 patients with paroxysmal AF were randomized to point-by-point radiofrequency catheter isolation of pulmonary veins $(\mathrm{PVI})$ under general anesthesia $(n=77)$ or conscious sedation $(n=73)$. Adenosine-mediated dormant conduction was eliminated in all patients. Antiarrhythmic medication was discontinued after PVI. During twelve months of follow-up, all patients underwent four times 7-day ECG monitorings.

Results. There was no difference between groups in AF recurrence (28.6\% vs. $31.5 \%, P=0.695)$. Patients in conscious sedation had longer procedure times ( $160 \pm 32.1$ vs. $132 \pm 31.5 \mathrm{~min}, P<0.001)$, longer RF energy application times ( $40 \pm 15$ vs. $29 \pm 11 \mathrm{~min}, P<0.001$ ) and longer fluoroscopy times (6.2 $\mathrm{min} \pm 5.3$ vs. $4.3 \mathrm{~min} \pm 2.2, P<0.001$ ) with similar complication rates.

Conclusion. Conscious sedation is not inferior to general anesthesia in regard to arrhythmia recurrence or complication rates of catheter ablation of paroxysmal atrial fibrillation. However, it is associated with longer procedure times, longer time of radiofrequency energy application and longer fluoroscopy times.

Key words: general anesthesia, conscious sedation, atrial fibrillation, catheter ablation, adenosine, dormant conduction, arrhythmia recurrence, intracardiac echocardiography

Received: November 16, 2019; Revised: March 10, 2020; Accepted: March 10, 2020; Available online: April 6, 2020

https://doi.org/10.5507/bp.2020.012

(c) 2021 The Authors; https://creativecommons.org/licenses/by/4.0/

${ }^{a}$ Department of Internal Medicine I - Cardiology, University Hospital Olomouc, Czech Republic

${ }^{b}$ Department of Anesthesiology and Intensive Care Medicine, University Hospital Olomouc, Czech Republic

'Cardiovascular Centre, Tomas Bata Regional Hospital, Zlin, Czech Republic

${ }^{d}$ Department of Radiology, University Hospital Olomouc, Czech Republic

${ }^{e}$ Department of Biophysics, Faculty of Medicine and Dentistry, Palacky University Olomouc, Czech Republic

Corresponding author: Tomas Skala, e-mail: tomasskala@gmail.com

\section{BACKGROUND}

Atrial fibrillation (AF) is the most common sustained arrhythmia. It remains to have a significant impact on cardiovascular morbidity ${ }^{1}$. Catheter ablation (RFA) is significantly more effective in terms of arrhythmia recurrence rate than antiarrhythmic medication ${ }^{2}$. Dominant sources of triggers starting AF are in pulmonary veins (PV). PV isolation (PVI) is thus the cornerstone of the non-pharmacological treatment of paroxysmal AF (ref. $\left.{ }^{3}\right)$. RFA is a complex procedure that can last for several hours. For the duration of the procedure, the patient needs to remain motionless on the operation table. This is by itself far from comfortable. Moreover, the radio-frequency (RF) energy is very often perceived as very painful. With regards to painfulness of this procedure, some type of anesthesiology care is undoubtedly necessary. Generally speaking, two options are available: conscious sedation and general anesthesia.

Conscious sedation (CS) refers to administration of pain-relieving drugs resulting in a quantitative influ- ence on consciousness, with spontaneous ventilation preserved.

General anesthesia (GA) refers to a treatment procedure resulting in an elimination of perception of all stimuli, including pain. The ability to breathe spontaneously may be impaired based on the level of anesthesia.

There are several studies comparing these two approaches. Data on the impact of the type of anesthesiology care in patients in whom intracardiac echocardiography (ICE) and elimination of adenosine-mediated dormant conduction (DC) is used are very scarce.

\section{METHODS}

\section{Study design}

This study is a non-commercial, investigator-initiated, single-center, prospective, randomized, open-label, interventional, parallel-design trial.

We aim to evaluate the impact of the type of anesthesiology care on RFA of paroxysmal AF. 


\section{Clinical hypothesis}

When using ICE, computed tomography (CT) model of left atrium (LA) merged with LA electro-anatomical map and elimination of DC after adenosine challenge, CS is not inferior to GA regarding the arrhythmia recurrence rate after RFA of paroxysmal AF.

\section{Inclusion criteria}

Paroxysmal AF; $\geq 3$ episodes of AF in the last 6 months documented on ECG or on a Holter ECG monitoring; Sinus rhythm (SR) at the beginning of RFA; Age $>18$ years; a signed informed consent for the study (ICF).

\section{Exclusion criteria}

Persistent or long-standing persistent AF; Structural heart disease; Moderate-to-severe or severe valve disease or history of a valve disease surgery; Left ventricular ejection fraction (LVEF) $<35 \%$; Presence of intra-cardiac thrombi; Pregnancy; Breast feeding; Uncorrected congenital heart disease; Obstructive cardiomyopathy; Active myocarditis; Constrictive pericarditis; Untreated hypothyroidism or hyperthyroidism; Chronic kidney disease with a glomerular filtration rate $<30 \mathrm{~mL} / \mathrm{min}$; Chronic dialysis treatment; Presence on the urgent waiting list for a heart transplant; Recipient of any major organ transplant; Malignancy; Known to be human immunodeficiency virus positive; History of alcohol or illicit drug abuse disorder.

\section{The primary end-point}

Arrhythmia recurrence rate twelve months after catheter ablation.

\section{The secondary end-points}

RFA procedure duration; Fluoroscopy time; Total RFA burn time.

\section{Patient group}

A total of 150 patients indicated for RFA of paroxysmal AF were include in the study. Patients were classified as having paroxysmal $\mathrm{AF}$ according to current guidelines ${ }^{3}$. The written ICF was obtained from all subjects.

\section{Procedures before catheter ablation}

Transesophageal and transthoracic echocardiography within 24 hours before RFA. Cardiac CT focused on PV anatomy within 7 days before RFA.

\section{Echocardiography}

A standardized trans-thoracic and trans-esophageal echocardiography were done in all patients 1-24 hours before RFA. Intracardiac thrombi were excluded.

The measured parameters were LA diameter in parasternal long axis view, LA volume, LVEF, left atrial appendage $($ LAA) outflow speed $(\mathrm{cm} / \mathrm{s})$.

\section{Computed tomography}

64-slice LightSpeed VCT scanner (General Electrics, Milwaukee, USA) was used in all participants.
The range of the examination was from the bifurcation of the trachea to the heart apex.

CT parameters: tube voltage of $120 \mathrm{kV}$, pitch 0.984:1, collimation $64 \times 0.625 \mathrm{~mm}$ and gantry rotation $0.4 \mathrm{~s}$, ECG gating was not used.

The participants in both groups received intra-venously $70 \mathrm{~mL}$ of the iodinated contrast agent Iopromide (Ultravist ${ }^{\circledR}$ 370, Bayer Healthcare, Berlin, Germany) with a flow rate of $4 \mathrm{~mL} / \mathrm{s}$, followed by $30 \mathrm{~mL}$ of saline flush. The delay of data acquisition was triggered using the "bolus tracking" technique; the region of interest was located in the LA.

All examinations were performed with anatomically adapted tube current modulation based on attenuation profiles in the antero-posterior and lateral directions.

The CT images were reconstructed with a slice thickness of $0.625 \mathrm{~mm}$ using the standard filtered back-projection method with kernel Standard.

\section{Randomization}

Patients were randomized in a 1:1 ratio to receive either GA $(n=77)$ or CS $(n=73)$.

\section{Anticoagulation therapy management before catheter ablation}

Oral anticoagulation was uninterrupted during the ablation procedure in case of Warfarin.

In case of direct anticoagulants one dose was skipped before ablation. This dose was administered immediately after the end of ablation.

\section{Anesthetic care}

Blood pressure was measured invasively using right radial arterial link in all patients.

\section{General anesthesia}

At the beginning of the procedure, before femoral veins cannulation, we intravenously administered sufentanil (Sufentanil Torrex; $0.5 \mathrm{ug} / \mathrm{kg}$ ), propofol (Diprivan; $1-2 \mathrm{mg} / \mathrm{kg}$ ) and rocuronium (Esmeron; $0.6 \mathrm{mg} / \mathrm{kg}$ ) with a subsequent orotracheal intubation and mechanical ventilation. The GA was then managed using an inhalation anesthetics sevoflurane (Sevorane Baxter; 100\%) to achieve minimal alveolar concentration (MAC) 0.7. Sufentanil (5-10 ug) was administered as a single dose intermittently when needed. Pressure-controlled mechanical ventilation was used with a volume of $7-8 \mathrm{~mL} / \mathrm{kg}$ and ventilation rate of $10-12$ breaths/min. When the mean arterial pressure dropped below $65 \mathrm{mmHg}$, noradrenaline (norepinephrinum $1,000 \mathrm{mg} / \mathrm{mL} ; 0.5-12 \mu \mathrm{g} / \mathrm{min}$ to achieve mean arterial pressure above $65 \mathrm{mmHg}$ ) was used. After RFA, patients were extubated and subsequently monitored on an intermediate in-patient department until the next morning.

\section{Conscious sedation}

At the beginning of the procedure, before femoral veins cannulation, we administered fentanyl (Fentanyl Torrex $50 \mu \mathrm{g} / \mathrm{mL} ; 100 \mathrm{ug}$ single dose) intravenously and started a continuous infusion of midazolam hydrochlo- 
ride (Dormicum; $0.03-0.2 \mathrm{mg} / \mathrm{kg} / \mathrm{h}$ ). The speed of the continuous infusion was titrated to achieve the level of sedation (Richmond Agitation-Sedation Scale) RASS -2 to -3 . Femoral veins were cannulated with local anesthesia using Supracain 4\% (1 mL of Supracain contains $40 \mathrm{mg}$ of articaine hydrochloride and $0.006 \mathrm{mg}$ of epinephrine hydrochloride), $6 \mathrm{~mL}$ in each groin.

After RFA, patients were monitored on an intermediate in-patient department until the next morning.

\section{Catheter ablation}

Two steerable transseptal sheaths (Agilis ${ }^{\mathrm{TM}} \mathrm{NxT}$ Steerable Introducer, St. Jude Medical) were introduced via right femoral vein.

Two sheaths were introduced via left femoral vein for intra-cardiac echocardiography probe (AcuNav ultrasound catheter, Siemens Healthineers, USA) and decapolar diagnostic coronary sinus catheter (Inquiry ${ }^{\mathrm{TM}}$, St. Jude Medical).

Access to LA was acquired via double transseptal puncture. We have used Carto $3^{\mathrm{TM}}$ (Biosense Webster) in all patients to get a 3D electro-anatomical map. We have used a fast-anatomical map (FAM) consistently in all patients. CartoMerge ${ }^{\mathrm{TM}}$ technology was used to merge electro-anatomical map with CT model. Navistar ${ }^{\mathrm{TM}}$ ablation catheter (Biosense Webster) was used for a point-bypoint wide-antral RFA (Pic. 1) in all patients to achieve isolation of ipsilateral PVs.

Ablation energy was set to $25-30 \mathrm{~W}$ with cool flow of $20 \mathrm{~mL} / \mathrm{min}$. To validate PV isolation (entry block), Lasso ${ }^{\mathrm{TM}}$ catheter (Biosense Webster) was used. A direct current cardioversion was performed in case of ongoing AF prior to final check for PVI. After PVI, we did not use inducibility testing or provocation of extra-pulmonary triggers. In case of a typical atrial flutter documentation, a cavo-tricuspid isthmus (CTI) ablation was allowed. Extrapulmonary ablation other than CTI was not performed. We waited for $20 \mathrm{~min}$ after PVI and then we intravenously applied adenosine to test for a dormant conduction. At least $18 \mathrm{mg}$ of adenosine was used for the test.

A second- or third-degree atrioventricular block was needed for the dose of adenosine to have been considered sufficient.

In PVs with conduction recovery after adenosine testing, additional ablation was performed until DC was eliminated. The procedure was ended, once all PVs with conduction recovery were re-isolated.

Subsequently, the catheters were retracted from LA and based on the administered dose of heparin, a protamine-sulfate (Protamin ME; 5000 I.U./mL) was administered to negate the heparin effect. A peroral anticoagulation was started immediately or it went on in case of a non-interrupted anticoagulation.

Wide encircling lesions around ostia of ipsilateral pulmonary veins (CARTO3 electroanatomical model of left atrium, superposition with computed tomography model; postero-anterior view). Red dots $=$ ablated areas.

\section{RFA procedure duration definition}

Time from when the patient laid on the operation

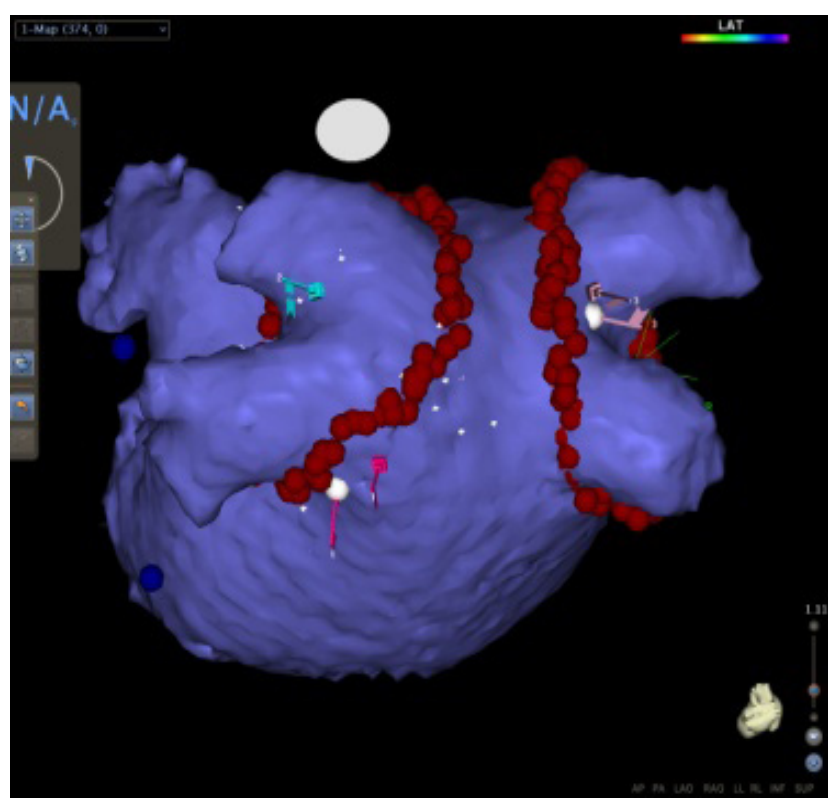

Fig. 1. CARTO3 left atrium3D model.

table until he or she was transferred into a hospital bed fully conscious.

\section{Follow-up post-ablation}

All antiarrhythmic medication was stopped immediately after RFA. All patients were followed in the outpatient department of our institution during the whole follow-up (FU).

A blanking period was set as 0-3 months after RFA. Arrhythmia recurrence was managed using antiarrhythmic medication and cardioversion if necessary. During the blanking period, AF recurrences were not considered an RFA failure and a cardioversion was allowed. Antiarrhythmic drugs were also allowed during the blanking period.

The first clinical visit was performed before the end of the third month after RFA and at this visit all potential antiarrhythmic medication was stopped if it was not stopped before. Antiarrhythmic drugs were not allowed after the end of third month or their use was considered as ablation failure / arrhythmia recurrence. Amiodarone was not allowed after RFA or its use was considered as ablation failure / arrhythmia recurrence.

Every 3 months after RFA (3, 6, 9 and 12 months after RFA), a 7-days ambulatory ECG monitoring was done in all patients.

Any documented arrhythmia lasting more than $30 \mathrm{sec}-$ onds was considered as an arrhythmia recurrence.

\section{Statistical evaluation}

Statistical analysis was done the $12^{\text {th }}$ month after ablation. The statistical software IBM SPSS Statistics ver. 22 was used to data analysis.

For nominal parameters, the subgroups of patients were compared using Chi-square test or Fisher's exact test.

Continuous parameters were compared using te MannWhitney U-test. Data normality was tested using Shapiro- 
Wilk test. The results are presented as means \pm SD and the level of significance was 0.05 .

\section{RESULTS}

\section{The difference between groups}

A total of 150 patients were enlisted in the study, 105 men and 45 women. The baseline clinical and echocardiographic characteristic of the group are depicted in Table 1. There was no significant difference between CS and GA in any baseline clinical or echocardiographic parameter except for a more frequent statin therapy in the CS group.

\section{Additional catheter ablation after pulmonary veins isolation}

In this patient group, we did not perform any additional catheter ablation after PVI except CTI in some cases. There was nosignificant difference between CS and GA in number of CTI ablations (Table 2).

\section{Procedural characteristics}

RFA in the CS group lasted longer (160 min \pm 32.1 vs. $132 \min \pm 31.5, P<0.001$ ). A total burn time (total length of RF energy application) was longer in the CS group (40 \pm 15 vs. $29 \pm 11 \mathrm{~min} . P<0.001)$. Also, total fluoroscopy time was longer in the CS group (6.2 $\mathrm{min} \pm 5.3$ vs. $4.3 \mathrm{~min}$
Table 2. Cavotricuspid isthmus ablation.

\begin{tabular}{lccc}
\hline & $\begin{array}{c}\text { Conscious } \\
\text { sedation }\end{array}$ & $\begin{array}{c}\text { General } \\
\text { anesthesia }\end{array}$ & $P$ \\
\hline $\begin{array}{l}\text { Cavotricuspid } \\
\text { isthmus ablation }\end{array}$ & $28(38.4 \%)$ & $30(39.0 \%)$ & 0.939 \\
\hline
\end{tabular}

Table 3. Catheter ablation characteristics.

\begin{tabular}{lccc}
\hline & $\begin{array}{c}\text { Conscious } \\
\text { sedation }\end{array}$ & $\begin{array}{c}\text { General } \\
\text { anesthesia }\end{array}$ & $P$ \\
\hline $\begin{array}{l}\text { Procedure time } \\
\text { (min) }\end{array}$ & $159.6 \pm 31.5$ & $137.2 \pm 32.1$ & $<0.0001$ \\
$\begin{array}{l}\text { Fluoroscopy time } \\
\text { (min) }\end{array}$ & $6.2 \pm 5.3$ & $4.3 \pm 2.2$ & $<0.001$ \\
$\begin{array}{l}\text { Total burn time } \\
(\text { min })\end{array}$ & $43.2 \pm 15.1$ & $31.2 \pm 11.1$ & $<0.0001$ \\
\hline
\end{tabular}

$\pm 2.2, P<0.001)$. These parameters are summed in Table 3 and depicted in Fig. 2, 3, 4.

\section{Adenosine-mediated dormant conduction}

After PVI and a subsequent adenosine administration, DC was present in 23 patients (40.4\%) in the CS group and in 24 patients $(34.3 \%)$ in the GA group. The difference was not significant (Table 4).

Table 1. Baseline clinical and echocardiographic characteristics of the patient group.

\begin{tabular}{|c|c|c|c|}
\hline & Conscious sedation & General anesthesia & $P$ \\
\hline Male sex & $54(70 \%)$ & $51(69.9 \%)$ & 0.972 \\
\hline Age & $56.2 \pm 10.9$ & $56.9 \pm 11$ & 0.574 \\
\hline Weight & $91.8 \pm 17.3$ & $87.6 \pm 17.4$ & 0.137 \\
\hline Body mass index & $28.6 \pm 4.9$ & $28.3 \pm 4.4$ & 0.542 \\
\hline LA diameter $(\mathrm{mm})$ & $41.7 \pm 6.4$ & $42.1 \pm 6.6$ & 0.767 \\
\hline LAA outflow velocity $(\mathrm{cm} / \mathrm{s})$ & $79.3 \pm 28.2$ & $70.3 \pm 28.0$ & 0.061 \\
\hline LVEF (\%) & $56.4 \pm 6.0$ & $56.6 \pm 4.2$ & 0.389 \\
\hline Arterial hypertension & $44(60.3 \%)$ & $48(62.3 \%)$ & 0.867 \\
\hline Diabetes mellitus & $7(9.6 \%)$ & $9(11.7 \%)$ & 0.794 \\
\hline Heart failure & $3(4.1 \%)$ & $5(6.5 \%)$ & 0.720 \\
\hline Coronary artery disease & $2(2.7 \%)$ & $4(5.2 \%)$ & 0.682 \\
\hline Myocardial infarction & $1(1.4 \%)$ & $3(3.9 \%)$ & 0.620 \\
\hline Hyperlipidemia & $28(38.4 \%)$ & $23(29.9 \%)$ & 0.304 \\
\hline Stroke & $4(5.5 \%)$ & $6(7.9 \%)$ & 0.746 \\
\hline Propafenone & $25(34.2 \%)$ & $28(36.4 \%)$ & 0.865 \\
\hline Sotalol & $7(9.6 \%)$ & $5(6.5 \%)$ & 0.556 \\
\hline Amiodarone & $17(23.3 \%)$ & $16(20.8 \%)$ & 0.844 \\
\hline Dronedarone & $1(1.4 \%)$ & $0(0 \%)$ & 0.487 \\
\hline Beta-blockers & $48(65.8 \%)$ & $57(74.0 \%)$ & 0.290 \\
\hline Statin & $27(37.0 \%)$ & $16(20.8 \%)$ & 0.032 \\
\hline Calcium channel blockers & $16(21.9 \%)$ & $15(19.5 \%)$ & 0.84 \\
\hline ACE inhibitors & $29(39.7 \%)$ & $27(35.1 \%)$ & 0.614 \\
\hline Angiotensin II receptor blockers & $9(12.3 \%)$ & $17(22.1 \%)$ & 0.134 \\
\hline
\end{tabular}




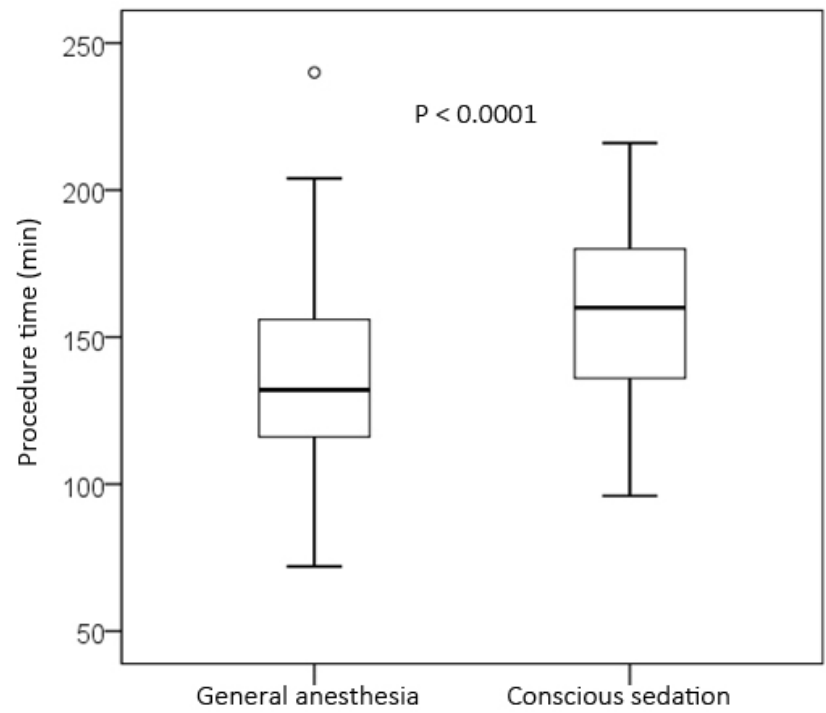

Fig. 2. Procedure time.

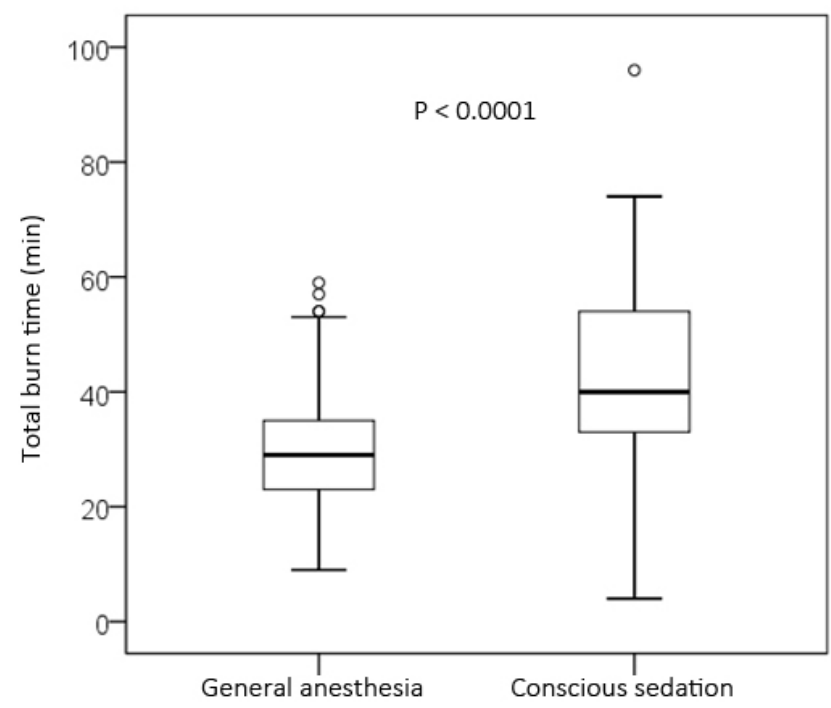

Fig. 3. Total burn time.

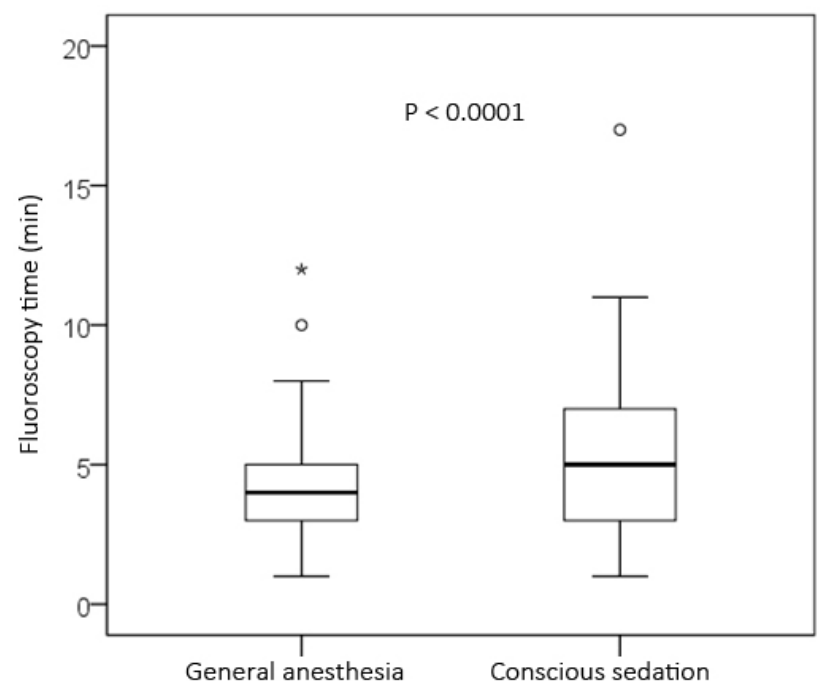

Fig. 4. Fluoroscopy time.
Table 4. The presence of adenosine-mediated dormant conduction.

\begin{tabular}{lccc}
\hline & $\begin{array}{c}\text { Conscious } \\
\text { sedation }\end{array}$ & $\begin{array}{c}\text { General } \\
\text { anesthesia }\end{array}$ & $P$ \\
\hline $\begin{array}{l}\text { Dormant } \\
\text { conduction }\end{array}$ & $23(40.4 \%)$ & $24(34.3 \%)$ & 0.58 \\
\hline
\end{tabular}

Table 5. Arrhythmia recurrence rate after catheter ablation.

\begin{tabular}{lccc}
\hline & $\begin{array}{c}\text { Conscious } \\
\text { sedation }\end{array}$ & $\begin{array}{c}\text { General } \\
\text { anesthesia }\end{array}$ & $P$ \\
\hline $\begin{array}{l}\text { Arrhythmia } \\
\text { recurrence rate }\end{array}$ & $23(31.5 \%)$ & $22(28.6 \%)$ & 0.695 \\
\hline
\end{tabular}

\section{Complications of catheter ablation}

Two patients presented with a femoral artery pseudoaneurysm (1 in CS group, 1 in GA group). One case was resolved using an ultrasound-guided manual compression; the other patient had to undergo surgery. In the CS group, we documented one case of a transient ischemic attack manifested as diplopia. The neurological symptoms receded completely in less than $60 \mathrm{~min}$. A subsequent CT of the brain revealed nosigns of ischemia. In the whole group, there were no cases of cardiac tamponade, atrioesophageal fistula, stroke or any other severe complication.

\section{Arrhythmia recurrence rate after ablation}

At the end of the ablation procedure, all PVs were isolated in all patients. 12 months after RFA, an arrhythmia recurrence was documented in 23 patients $(31.5 \%)$ in the CS group and in 22 patients (28.6\%) in the GA group. The difference was not significant (Table 5).

\section{DISCUSSION}

Due to different pain thresholds, sedation is not entirely effective in some patients. A painful RFA cannot only be subjectively unpleasant but it can also lead to a movement of the patient with an electro-anatomical map shift. This may lead to an unsatisfactory localization of anatomical details in the cardiac chamber of interest or to a need for a new map. Either of these cases can lead to prolongation of the procedure. Considerable respiratory excursions cause by painful RF applications also worsen contact of the catheter with myocardial tissue. Using catheters with contact-force, Chikata et al. demonstrated that RFA in GA improves the contact force and thus increases the rate of PVI made by just one encircling lesion (first pass PVI) $(50.5 \%$ vs. $34.8 \%, P=0.04)\left(\right.$ ref. $\left.^{4}\right)$.

Generally speaking, GA is perceived as a procedure extending the duration of RFA but the opposite was true in our study. We demonstrated that a complete elimination of painful perceptions during GA makes RFA faster. The absence of stopping of RF energy applications, significant patient movement and excessive respiratory excursions leads to a shorter total RF energy application time (total burn time) and also to a shorter fluoroscopic time. 
It is inadvisable to underestimate even the subjective unpleasant perception itself. Fewer patients ablated in CS are willing to undergo a repeated procedure compared to patients ablated in GA (ref. ${ }^{5}$ ).

It could be tempting to blame a poorly led CS for the painful perceptions. But the pain threshold and tolerance differ from patient to patient. In a small number of patients, due to significant painful sensations, it is very difficult to finish RFA despite potent doses of analgesics. On the other hand, it is not difficult to administer an excessive dose of analgesics in such a situation, leading to a cessation of breathing. This obviously results in a rapid response in regards of the patients' management and often also to a significant movement of his or her body and a need to make a new electro-anatomical map.

A very calm course of RFA under GA in our study was associated with a decrease in the procedure length. This was also documented in the study by Di Biase et al. with a shorter procedure length in GA patients $(2.4 \pm 1.4$ vs 3.6 $\pm 1.1 \mathrm{~h}, P<0.01$ ) (ref. ${ }^{6}$ ). Other trials had different results. Wasserlauf et al. presented outcomes in Cryobaloon ablation patients. In their study, a moderate sedation reduced laboratory time compared to GA (280.4 $\pm 54.1 \mathrm{~min}$ vs $245.5 \pm 54.7 \mathrm{~min}, P<0.001$ ) (ref. $\left.{ }^{7}\right)$. In a study with remote magnetic ablation, Bun et al. concluded that GA is not superior to local anesthesia $(237 \pm 50 \mathrm{~min}$ vs. $240 \pm 61$ min, $P=0.84$ ) $\left(\right.$ ref. $^{8}$ ). In a small randomized trial with $\mathrm{RF}$ energy ablation, overall procedural times were comparable in GA and analgosedation groups (111.2 $\pm 16.3 \mathrm{~min}$ vs $104.8 \pm 25 \min , P=\mathrm{NS})\left(\right.$ ref. $\left.^{5}\right)$.

Painful sensations during RFA can lead to a need for a decrease in RF energy output and a potentially inefficient ablation. Di Biase et al. demonstrated a higher long-term RFA efficacy in GA patients ( $88 \%$ vs $69 \%, P<0.001)$ and also a lower $\mathrm{PV}$ reconnection rate during a redo procedure ( $19 \%$ vs $42 \%, P=0.003$ ) $\left(\right.$ ref. $\left.^{6}\right)$. On the contrary, studies with remote magnetic ablation ${ }^{8}$ and Cryobaloon ${ }^{7}$ documented similar long-term arrhythmia recurrence rate in CS and GA patients.

We can potentially demonstrate an insufficient RFA in CS patients using an adenosine test ${ }^{9}$. We have already demonstrated, that by elimination of DC by additional ablation it is possible to equalize long-term arrhythmia recurrence rate in patients with DC and without DC (ref. $\left.{ }^{10}\right)$. In our study, we documented no significant difference in the presence of adenosine-mediated DC between the SC and GA groups. We thus have no evidence of an insufficient ablation in any of those groups. We can only speculate that the reason could be a constant employment of ICE with a real-time monitoring of the movement and localization of the ablation catheter. However, the presence of DC can be influenced by the type of anesthetic care. Narui et al. documented an adenosine-mediated DC more frequently in patients in a deeper sedation in comparison with a milder sedation $(19.2 \%$ vs $13.0 \%, P=0.01)$. In our study, we did not observe a significant difference in the presence of DC between the groups. Without data from a redo procedure, we can only speculate if this is caused by a comparably effective CS and GA in similarly performed PVI or by differently effective CS and GA, counterbal- anced with a differently performed RFA. Nevertheless, we have shown that we can achieve comparable RFA outcomes in CS and GA patients if we use ICE and eliminate potential DC.

We can also only speculate that the minimal complications rate in our study, and none directly linked to GA, is due to the routine employment of ICE. Potential thrombi could be sucked out before manifestation of a cardioembolic event even during GA. One can lower the power setting of RF energy delivery when the catheter is in a close proximity to esophagus on ICE image and does not need to rely on a pain sensation told by the patient in CS. We did not confirm the often-mentioned concern about a higher complication rate in GA patients.

\section{Study limitations}

This study was not blinded but blinding was not feasible due to the nature of the study.

The study power was not analysed before the trial. Thus the number needed to confirm statistical significance may not have been met. Nevertheless, the number of patients included in this trial was comparable with similar trials. This trial was single-centre only. In our institution, for AF ablation, GA is mainly used. This might be a source of potential error and one probable explanation for the differences between groups. Significantly more men than women were included, however without a significant difference in the rate of men between CS and GA. In this patient group, we did not perform any additional RFA after PVI, except a CTI ablation in a significant percentage of the patient group. Even a slight possibility of typical atrial flutter on any previous ECGs led us to CTI ablation. The ratio of this ablation was higher in comparison with previous studies ${ }^{9}$ since our threshold for a CTI ablation is significantly lower because of the simplicity, safety and efficacy of this ablation procedure when steerable sheaths and ICE are available. Nevertheless, there was no significant difference in CTI ablations rate between CS and GA. Another potential study limitation is the absence of contact-force catheters. These were not routinely available at our institution at the beginning of the study and we did not use them in these patients from there on in order not to distort the results of the study.

\section{CONCLUSION}

Conscious sedation is not inferior to general anesthesia regarding arrhythmia recurrence or complication rate of catheter ablation of paroxysmal atrial fibrillation. However, it is associated with longer procedure times, longer radiofrequency energy application duration and longer fluoroscopy times.

\section{ABBREVIATIONS}

AF, Atrial fibrillation; RFA, Catheter ablation; RF, Radio-frequency; PV, Pulmonary veins; PVI, Pulmonary veins isolation; CS, Conscious sedation; CA, General 
anesthesia; ICE, Intracardiac echocardiography; DC, Dormant conduction; LVEF, Left ventricular ejection fraction; SR, Sinus rhythm; ICF, Informed consent for the study; INR, international normalized ratio; FU, Followup; LA, Left atrial; CT, Computed tomography; LAA, left atrial appendage; CTI, Cavo-tricuspid isthmus; MAC, Minimal alveolar concentration; FAM, Fast-anatomical map.

Acknowledgement: This trial is investigator-led and noncommercial. No sources of funding outside standard health insurance payments were used.

Author contributions: All authors substantially contributed to the conception of the study, to the acquisition, analysis and interpretation of data and have approved the final version of the manuscript.

Conflict of interest statement: The authors state that there is no conflict of interest regarding the publication of this article.

\section{REFERENCES}

1. Kirchhof $P$, Benussi $S$, Kotecha D, Ahlsson A, Atar D, Casadei B Castella M, Diener HC, Heidbuchel H, Hendriks J, Hindricks G, Manolis AS, Oldgren J, Popescu BA, Schotten U, Van Putte B, Vardas P, Agewall S, Camm J, Baron Esquivias G, Budts W, Carerj S, Casselman F, Coca A, De Caterina R, Deftereos S, Dobrev D, Ferro JM, Filippatos G, Fitzsimons D, Gorenek B, Guenoun M, Hohnloser SH, Kolh P, Lip GY, Manolis A, McMurray J, Ponikowski P, Rosenhek R, Ruschitzka F, Savelieva I, Sharma S, Suwalski P, Tamargo JL, Taylor CJ, Van Gelder IC, Voors AA, Windecker S, Zamorano JL, Zeppenfeld K. 2016 ESC Guidelines for the management of atrial fibrillation developed in collaboration with EACTS. Eur J Cardiothorac Surg 2016; 0(5):e1-e88.

2. Morillo CA1, Verma A, Connolly SJ1, Kuck KH3, Nair GM4, Champagne J, Sterns LD, Beresh H1, Healey JS, Natale A; RAAFT-2 Investigators. Radiofrequency ablation vs antiarrhythmic drugs as first-line treatment of paroxysmal atrial fibrillation (RAAFT-2): a randomized trial. JAMA 2014;311(7):692-700.
3. Calkins H, Hindricks G, Cappato R, Kim YH, Saad EB, Aguinaga L, Akar JG, Badhwar V, Brugada J, Camm J, Chen PS, Chen SA, Chung MK, Nielsen JC, Curtis AB, Davies DW, Day JD, d'Avila A, de Groot NMSN, Di Biase L, Duytschaever M, Edgerton JR, Ellenbogen KA, Ellinor PT, Ernst S, Fenelon G, Gerstenfeld EP, Haines DE, Haissaguerre M, Helm RH, Hylek E, Jackman WM, Jalife J, Kalman JM, Kautzner J, Kottkamp H, Kuck KH, Kumagai K, Lee R, Lewalter T, Lindsay BD, Macle L, Mansour M, Marchlinski FE, Michaud GF, Nakagawa $\mathrm{H}_{\text {, }}$ Natale A, Nattel S, Okumura K, Packer D, Pokushalov E, Reynolds MR, Sanders P, Scanavacca M, Schilling R, Tondo C, Tsao HM, Verma A, Wilber DJ, Yamane T. 2017 HRS/EHRA/ECAS/APHRS/SOLAECE expert consensus statement on catheter and surgical ablation of atrial fibrillation: Executive summary. Europace 2018;20(1):157-208.

4. Chikata A, Kato T, Yaegashi T, Sakagami S, Kato C, Saeki T, Kawai K, Takashima S, Murai H, Usui S, Furusho H, Kaneko S, Takamura M. General anesthesia improves contact force and reduces gap formation in pulmonary vein isolation: a comparison with conscious sedation. Heart Vessels 2017;32(8):997-1005.

5. Stašková $K$, Bulava $A$, Tesařík $R$, Toušek $F$. Radiofrequency cathete ablation of atrial fibrillation performed under general anesthesia: Results of a unicentric randomized trial. Vnitr Lek 2017;63(3):163-9 (In Czech).

6. Di Biase L, Conti S, Mohanty P, Bai R, Sanchez J, Walton D, John A, Santangeli P, Elayi CS, Beheiry S, Gallinghouse GJ, Mohanty S, Horton R, Bailey S, Burkhardt JD, Natale A. General anesthesia reduces the prevalence of pulmonary vein reconnection during repeat ablation when compared with conscious sedation: results from a randomized study. Heart Rhythm 2011;8(3):368-72.

7. Wasserlauf J, Knight BP, Li Z, Andrei AC, Arora R, Chicos AB, Goldberger JJ, Kim SS, Lin AC, Verma N, Bohn MM, Passman RS. Moderate Sedation Reduces Lab Time Compared to General Anesthesia during Cryoballoon Ablation for AF Without Compromising Safety or Long-Term Efficacy. Pacing Clin Electrophysiol 2016;39(12):1359-65.

8. Bun SS, Latcu DG, Allouche E, Errahmouni A, Saoudi N. General anesthesia is not superior to local anesthesia for remote magnetic ablation of atrial fibrillation. Pacing Clin Electrophysiol 2015;38:391-7.

9. Macle L, Khairy P, Weerasooriya R, Novak P, Verma A, Willems S, for the ADVICE trial. Adenosine-guided pulmonary vein isolation for the treatment of paroxysmal atrial fibrillation: An international, multicentre, randomised superiority trial. Lancet 2015;386:672-9.

10. Skala T, Precek J, Hutyra M, Moravec O, Tudos Z, Skalova J, Klementova O, Antonicka A, Zapletalova J, Taborsky M. Longterm outcome of paroxysmal atrial fibrillation catheter ablation with and without pulmonary vein dormant conduction after adenosine challenge. Biomed Pap Med Fac Univ Palacky Olomouc Czech Repub 2019 Mar 4. doi: 10.5507/bp.2019.005. [Epub ahead of print] 